\title{
Preference and consumption of a taste enhanced meat meal by older hospital patients: A pilot study
}

\author{
Maria Dermiki ${ }^{\mathrm{a}}$, Joanne Willway ${ }^{\mathrm{a}}$, Laura Sargent ${ }^{\mathrm{a}}$, James Kidman ${ }^{\mathrm{a}}$, Claire Anderson ${ }^{\mathrm{a}}$, \\ Orla B. Kennedy ${ }^{\mathrm{a}}$, Margot A. Gosney ${ }^{\mathrm{b}}$ and Lisa Methven ${ }^{\mathrm{a}, *}$ \\ ${ }^{\mathrm{a}}$ Department of Food and Nutritional Sciences, University of Reading, Whiteknights, Reading, UK \\ ${ }^{\mathrm{b}}$ Clinical Health Sciences, University of Reading, London Road, Reading, UK
}

\begin{abstract}
.
BACKGROUND: Older hospital patients are considered to be at risk of malnutrition due to insufficient dietary intake.

OBJECTIVE: To determine whether taste enhancement, using ingredients naturally high in umami compounds, increases preference and consumption of a meal by older hospital patients.

METHODS: 31 patients (65-92 years) on elderly care wards in a UK NHS Trust hospital took part in a single-blinded preference and consumption study. They tasted two meats (control and enhanced, presented in balanced order) and stated their preference. At lunch, control and enhanced cottage pie and gravy were served concurrently; patients were asked to consume ad libitum and intake was measured.

RESULTS: Taste enhanced meat was significantly preferred $(P=0.001)$. Although mean consumption was higher for the enhanced compared to control meal ( $137 \mathrm{~g}$ versus $119 \mathrm{~g}$ ), with higher levels of energy ( $103 \mathrm{kcal}$ versus $82 \mathrm{kcal})$ and protein ( $4.6 \mathrm{~g}$ versus $3.4 \mathrm{~g}$ ) consumed; differences were not significant.

CONCLUSIONS: Natural ingredients rich in umami taste compounds can successfully be used to increase preference of meat based meals by older hospital patients. Larger trials are needed to determine whether such increases in preference can significantly increase consumption.
\end{abstract}

Keywords: Malnutrition, taste enhancement, umami, older patients

\section{Introduction}

In the 2011 nutrition screening week, where patients admitted to care across the UK were screened for malnutrition using the Malnutrition Universal Screening Tool (MUST), it was found that $34 \%$ of patients admitted to elderly care wards were malnourished [1]. Many physiological, social and psychological fac-

*Corresponding author: Lisa Methven, Department of Food and Nutritional Sciences, University of Reading, Whiteknights, Reading, RG6 6AP, UK. Tel.: +44 118 3788714. E-mail: 1.methven@ reading.ac.uk. tors predispose older people to undernutrition. Among physiological factors, sensory impairment is important. Studies conclude that taste thresholds deteriorate with age [2], and with medication [3]. This can reduce satisfaction from food and impact on food intake [4].

Umami is savoury taste perception, stimulated by glutamic and aspartic acid and $5^{\prime}$-nucleotides [5]. The effect of taste enhanced food on liking and consumption by older people remains unclear. Monosodium glutamate (MSG) and flavourings added to nursing home residents' food $(n=50$, mean age $=82)$ increased satisfaction ratings [6]. Moreover, in another study its addition resulted in increased dietary intake and 
body weight of nursing home residents who received enhanced meals $(n=36)$ compared to a control $(n=31)$ [7]. One hospital study found that 40 of 43 patients increased calorie intake by minimum $10 \%$ when consuming MSG enhanced meals [6]. Two studies contradict these findings; there was no increase in intake by nursing home residents when food enhanced with flavour and/or MSG $(n=97$, age $>65)$ [8], or MSG alone $(n=53$, age $>65)$ was consumed [9]. The same group of researchers found no effect from flavour and/or MSG on liking and intake of soup consumed by free living older people $(n=120$, age $=72 \pm 6)[10]$. Potential reasons for differing study results include use of different MSG concentrations, different exposure times and different methods of addition.

There are few hospital studies, yet the high prevalence of undernutrition in older hospital patients suggests research is needed in this setting. Direct MSG addition is unacceptable to many consumers and less effective to achieve strong savoury taste than using natural ingredients where synergy between glutamate and 5 '-nucleotides is utilised [11]. The two aims of this study were to establish whether an increase in umami taste within meat, achieved through use of natural ingredients, could lead to (a) an increased preference for the meat and (b) increased consumption of a meal, by older hospital patients.

\section{Methods}

\subsection{Subjects}

Subjects recruited from elderly care wards at an NHS Foundation Trust (Royal Berkshire NHS Trust, Reading, UK). Inclusion criteria: age $>65$ years, ability to consent, abbreviated mini-mental state examination (MMSE) score above 18 (out of 30), ability to eat without assistance, non vegetarians, no relevant food allergy or intolerance. Subjects were recruited the day before they took part in the study, following advertisement of the study on the wards for more than 24 hours. Copies of the participant information sheet were left with patients while they considered if they wanted to take part. Potential subjects were able to discuss the study with hospital clinical staff and then the researchers met with interested patients. Ninety five suitable patients were identified, of whom 31 agreed to take part in the study. Consent forms were com- pleted and signed by the subjects and witnessed by the researcher.

This study was conducted according to the guidelines laid down in the Declaration of Helsinki and all procedures involving human subjects/patients were given favourable opinion to proceed by the Isle of Wight, Portsmouth and South East Hampshire research ethics committee (study number 10/H0501/58).

\subsection{Test foods}

Control recipes for gravy, minced meat (the minced beef plus stock and vegetables used as the base of the cottage pie) and cottage pie (the minced meat base plus mashed potato) were from the NHS Trust (Table 1). Natural umami ingredients incorporated into meat base during cooking were reduced salt soy sauce (Kikkoman, Netherlands) and concentrated tomato extract (Lycored, USA). Enhanced gravy contained reduced salt soy sauce. The combination and quantities used were selected following sensory and liking (older consumers) tests of various umami ingredients [11]. Cottage pies comprised of cooked minced meat base $(90 \mathrm{~g})$ plus mashed potato $(90 \mathrm{~g})$. Equivalent total sodium was assured in enhanced and control products by addition of sodium chloride to the control meat base only (Table 1). The level of salt added to the control $(0.30 \% \mathrm{w} / \mathrm{w}$, as normally used in this hospital recipe) equated to the sodium present in the umami-rich ingredients (declared on specifications) used in the enhanced recipe (soy sauce and concentrated tomato extract). Foods were cooked in the Trust kitchen and frozen $\left(-18^{\circ} \mathrm{C}\right)$. On study days, pies were heated for $40 \mathrm{~min}$ utes at $180^{\circ} \mathrm{C}$ (convection steam oven) and gravies reconstituted by heating and by adding corn flour. Nutritional profiles determined using Dietplan 6 (Forestfield, UK) (Table 1).

\subsection{Hospital procedure}

Volunteers were included based on inclusion criteria and written consent as explained above. They completed a hospital anxiety and depression score test (HADS, scale 0 to 42) and it was recorded whether or not they used dentures. Mid-morning, patients tasted samples of control and enhanced cooked minced meat base $(25 \mathrm{~g})$ in a balanced order and stated their preferred sample of the two. 
Table 1

Test food specifications and characteristics

\begin{tabular}{|c|c|c|c|c|}
\hline Ingredient (g) & $\begin{array}{c}\text { Control } \\
\text { meat }(g / 100 g)\end{array}$ & $\begin{array}{c}\text { Enhanced } \\
\text { meat }(\mathrm{g} / 100 \mathrm{~g})\end{array}$ & $\begin{array}{c}\text { Control } \\
\text { gravy }(\mathrm{g} / 100 \mathrm{~g})\end{array}$ & $\begin{array}{c}\text { Enhanced } \\
\text { gravy }(\mathrm{g} / 100 \mathrm{~g})\end{array}$ \\
\hline Minced Beef & 38.7 & 38.7 & 0 & 0 \\
\hline Onions & 12.9 & 12.9 & 2.2 & 2.2 \\
\hline Oil & 0.52 & 0.52 & 0.83 & 0.83 \\
\hline Tomato Puree & 1.3 & 1.3 & 1.8 & 1.8 \\
\hline Beef Stock & 0.46 & 0.46 & 2.2 & 2.2 \\
\hline Thyme & 0.11 & 0.11 & 0 & 0 \\
\hline Carrots & 12.9 & 12.9 & 0 & 0 \\
\hline Peas & 5.2 & 5.2 & 0 & 0 \\
\hline Cornflour & 2.6 & 2.6 & 4.5 & 4.5 \\
\hline Soy Sauce & 0.0 & 1.7 & 0 & 2.5 \\
\hline Tomato extract & 0.0 & 1.8 & 0 & 0 \\
\hline Salt & 0.15 & 0 & 0.22 & 0 \\
\hline Browning & 0 & 0 & 0.90 & 0.90 \\
\hline Water & 25.3 & 21.8 & 87.3 & 85.0 \\
\hline Nutritional Composition ${ }^{\mathrm{A}}$ : & \multicolumn{2}{|c|}{$\begin{array}{c}\text { Control Meal } \\
\text { per portion (per } 100 \mathrm{~g} \text { ) }\end{array}$} & \multicolumn{2}{|c|}{$\begin{array}{c}\text { Enhanced Meal }^{\mathrm{B}} \\
\text { per portion (per } 100 \mathrm{~g} \text { ) }\end{array}$} \\
\hline Energy (kcal) & \multicolumn{2}{|c|}{$221(77)$} & \multicolumn{2}{|c|}{$229(80)$} \\
\hline Protein & \multicolumn{2}{|c|}{$11.1(3.9)$} & \multicolumn{2}{|c|}{$11.7(4.1)$} \\
\hline Fat & \multicolumn{2}{|c|}{$8.3(2.9)$} & \multicolumn{2}{|c|}{$8.3(2.9)$} \\
\hline \multirow[t]{2}{*}{ Concentration of umami compounds $(\mathrm{g} / 100 \mathrm{~g})^{\mathrm{C}}$} & \multicolumn{2}{|c|}{ Minced meat } & \multicolumn{2}{|c|}{ Cottage pies with gravy ${ }^{\mathrm{D}}$} \\
\hline & Control & Enhanced & Control & Enhanced \\
\hline 5'-Adenosine monophosphate (AMP) & $0.006^{\mathrm{b}}$ & $0.010^{\mathrm{a}}$ & $0.006^{\mathrm{b}}$ & $0.007^{\mathrm{b}}$ \\
\hline $5^{\prime}$-Guanosine monophosphate (GMP) & $0.000^{\mathrm{b}}$ & $0.001^{\mathrm{ab}}$ & $0.001^{\mathrm{a}}$ & $0.001^{\mathrm{a}}$ \\
\hline $5^{\prime}$-Inosine monophosphate (IMP) & $0.004^{\mathrm{a}}$ & $0.003^{\mathrm{a}}$ & $0.003^{\mathrm{a}}$ & $0.002^{\mathrm{a}}$ \\
\hline Glutamic acid & $0.036^{\mathrm{b}}$ & $0.070^{\mathrm{a}}$ & $0.039^{\mathrm{b}}$ & $0.069^{\mathrm{a}}$ \\
\hline Aspartic Acid & $0.012^{\mathrm{d}}$ & $0.037^{\mathrm{a}}$ & $0.014^{\mathrm{c}}$ & $0.028^{\mathrm{b}}$ \\
\hline EUC & $0.29^{\mathrm{c}}$ & $0.77^{\mathrm{a}}$ & $0.38^{\mathrm{bc}}$ & $0.62^{\mathrm{ab}}$ \\
\hline
\end{tabular}

The consumption measurements were conducted on the same day during lunchtime (12:30). Lunch comprised of two plates, each containing a cottage pie $(180 \mathrm{~g})$, mixed vegetables $(50 \mathrm{~g})$ and gravy $(51 \mathrm{~g})$, along with any starter and dessert the patient had ordered. The two plates were presented concurrently, balanced left/right position on bedside table; the left/right position additionally balanced according to whether the patients were left/right handed. The participant was asked to try both pies and consume as much as they liked from both plates. Pre and post lunch weights of main course plated meals were recorded and the total meal and pie consumption was calculated. The methodology of testing control and enhanced food within one meal aimed to overcome issues of patient conditions changing daily, a recognised challenge for nutrition studies in an acute care setting.

\subsection{Sensory discrimination test for umami taste}

Healthy subjects ( $n=35$ (18 women), age: $20-40$ years old) were recruited for this study through email and asked to visit the sensory evaluation booths at the University of Reading, They were first asked to taste a small sample of MSG solution $(0.5 \% \mathrm{w} / \mathrm{w})$ in order to become familiar with umami taste. They were then asked to carry out two directional alternative forced choice (2-AFC) discrimination tests. Given the two samples of minced meat base, in balanced order, they were asked to state which tasted the most 'umami'. 
Table 2

Subject characteristics

\begin{tabular}{|c|c|c|c|}
\hline Characteristics & N, Mean or Median & $\%, \mathrm{SD}$ or $\mathrm{IQR}^{\mathrm{a}}$ & $\bar{n}$ \\
\hline Gender (Male/Female) & $11 / 20$ & $35 / 65$ & 31 \\
\hline Age (y) & 84.3 (mean) & $6.3(\mathrm{SD})$ & 31 \\
\hline Smoker (Y/N) & $3 / 28$ & $10 / 90$ & 31 \\
\hline Dentures (Y/N) & $14 / 15$ & $48 / 52$ & 29 \\
\hline MMSE score (scale 0-30) & 27 (median) & 8 (IQR) & 31 \\
\hline HADS total score (scale $0-42$ ) & 8.5 (median) & 5.3 (IQR) & 28 \\
\hline HADS depression (scale 0-21) & 3 (median) & 5 (IQR) & 28 \\
\hline
\end{tabular}

${ }^{\mathrm{a}} \mathrm{SD}=$ standard deviation, $\mathrm{IQR}=$ interquartile range.

This was then repeated for the two samples of cottage pie with gravy. Minced meat samples were reheated in a microwave (temperature $>75^{\circ} \mathrm{C}$ ). Cottage pies were cooked in a gas oven (core temperature $>80^{\circ} \mathrm{C}$ ). Samples were held in a heating trolley $\left(60-65^{\circ} \mathrm{C}\right)$ for a maximum of $30 \mathrm{~min}$ before serving.

\subsection{Chemical analysis}

Minced meat and the cottage pie mixed with gravy were analysed for their amino acid and 5'-nucleotides content, since these compounds contribute to the umami taste. Extraction, analysis of $5^{\prime}$-nucleotides content using Capillary Electrophoresis and analysis of amino acids content using GC-MS were conducted as described by Dermiki et al. [11]. The equivalent umami concentration (EUC) of the samples was then calculated using the following formula:

$$
Y=\sum a_{i} b_{i}+1218\left(\sum a_{i} b_{i}\right)\left(\sum a_{j} b_{j}\right)
$$

Where $\mathrm{Y}=$ the EUC, $\mathrm{a}_{\mathrm{i}}=$ the concentration of each umami amino acid, $a_{j}=$ the concentration of each umami $5^{\prime}$-nucleotide, $b_{i}=$ the relative umami concentration (RUC) for each umami amino acid to MSG, $b_{j}=$ the RUC for each umami $5^{\prime}$-nucleotide and $1218=$ a synergistic constant. All values were in $\mathrm{g} / 100 \mathrm{~g}$ [12]. The EUC equation is the concentration of monosodium glutamate MSG equivalent (defined as $\mathrm{g} / 100 \mathrm{~g}$ ) to the umami intensity given by the mixture of glutamic acid (Glu), aspartic acid (Asp) and the $5^{\prime}$-ribonucleotides.

\section{Statistical analysis}

Binomial expansion used for paired comparison test on preference data and 2-AFC data, and paired $t$-test on consumption data. For other comparisons MannWhitney tests were used. Variables categorised for analysis were: dentures (yes or no), age ( $<$ or $\geq 87$, the median age), depression score $(<$ or $\geq 3$, the median HAD depression score) and gender (male or female). Software used was XLSTAT (Addinsoft, version 2009) and DiffTest (Statbasics, version 2.00).

\section{Results}

31 hospital patients (20 women, 11 men; age 65-92, mean 84.3) were recruited to the study. An overall summary of subject characteristics can be seen in Table 2 . All subjects had relatively high MMSE scores (median 27 out of 30) suggesting good cognition, and low HADS scores (median HADS were 8.5 out of 21), suggesting low levels of anxiety and depression in these patients. Of those recruited, 30 completed the preference test and 29 completed the consumption test.

The taste enhanced meat base was significantly preferred (24 out of 30 subjects, $P=0.001$ ) (Table 3). Average consumption of enhanced cottage pie meal was higher than control meal $(137 \mathrm{~g}$ versus $119 \mathrm{~g})$, but was not significant $(\mathrm{t}(28)=1.1, P=0.30$; difference between means $18.2,95 \% \mathrm{CI}-17.3$ to 53.8 ). Twenty percent higher calories were consumed from the enhanced meal (103 kcal versus $82 \mathrm{kcal})$ although not significant $(\mathrm{t}(28)=1.4, P=0.17$; difference between means $21.2,95 \% \mathrm{CI}-9.6$ to 52.0$)$. The higher average protein content consumed $(4.6 \mathrm{~g}$ versus $3.4 \mathrm{~g}$ ) was also not significant $(\mathrm{t}(28)=1.8, P=0.09$; difference between means $1.2,95 \% \mathrm{CI}-0.19,2.7)$.

There were no significant effects on consumption from other factors measured including dentures, age or gender. Depression had a notable but not significant effect on consumption $(P=0.38)$. The median HAD depression score was 3 ; patients with higher than aver- 
Table 3

Preference and consumption of test meals

\begin{tabular}{|c|c|c|c|c|c|}
\hline \multirow[b]{2}{*}{ Variable } & \multicolumn{2}{|l|}{ Control } & \multicolumn{2}{|c|}{ Taste Enhanced } & \multirow[b]{2}{*}{$P$-value } \\
\hline & Median, Mean or $n$ & $\mathrm{SD}$ or $\%$ & Median, Mean or $n$ & $\mathrm{SD}$ or $\%$ & \\
\hline Preference of meat (number patients preferring this sample) & 6 & $20 \%$ & 24 & $80 \%$ & 0.001 \\
\hline Weight of meal ${ }^{\mathrm{a}}$ consumed (mean, g) & 119 & 76 & 137 & 74 & 0.30 \\
\hline Energy consumed from meal ${ }^{\mathrm{a}}$ (mean, kcal) & 82 & 60 & 103 & 65 & 0.17 \\
\hline Protein consumed from meal ${ }^{\mathrm{a}}$ (mean, $\mathrm{g}$ ) & 3.4 & 2.1 & 4.6 & 3.1 & 0.09 \\
\hline
\end{tabular}

${ }^{\mathrm{a}}$ meal $=$ pie with vegetables and gravy.

age depression score $(42 \%$ with $>3$ ) had a lower, but not significant, mean food intake $(225 \mathrm{~g}$ versus $280 \mathrm{~g}$ ).

Results from the sensory study confirmed that the enhanced meat base tasted more 'umami' $(P=0.045$; identified by 23 out of the 35 subjects), and 21 subjects identified the enhanced cottage pie with gravy as having a more umami taste which was not significant $(P=0.16)$.

\section{Discussion}

Using natural ingredients to enhance taste significantly increased preference for the meat. Mean consumption of enhanced meal was higher than for control meal, however, within the limitations of this acute study design, this was not significant. The average total consumption from both plates presented at lunch time was $185 \mathrm{kcal}, 8.0 \mathrm{~g}$ protein. The higher average proportion consumed of the enhanced meal compared to the control meal equated to $21 \mathrm{kcal}$ and $1.2 \mathrm{~g}$ protein which represented an increase, although non-significant, of $26 \%$ and $37 \%$ respectively of actual calories and protein consumed. Where intake is compromised this could have a large impact on the nutritional status of at risk individuals. However, for energy and protein the daily recommended values (DRV) for older people in residential care (FSA 2006 guidelines) are $1955 \mathrm{kcal}$ and $50 \mathrm{~g}$ respectively [13]. Therefore, the mean intake of the taste enhanced meal contributed to $5 \%$ of the daily recommended energy intake and 9\% of the protein intake. However, actual daily intake of older hospital patients is often lower than recommendations, one study recording mean daily intake at $1379 \mathrm{kcal}$ and $44.6 \mathrm{~g}$ protein over a 27 day period with 22 patients per day in one UK hospital [14]. Our results suggest that further support to increase nutrient intake from a single meal is needed. It is recommended that further studies on taste enhancement of meals for older patients are combined with macronutrient fortification.

The increase in preference was in agreement with previous studies which found that adding MSG to foods increased acceptability, the difference in our study being that this was achieved through the use of natural ingredients. The lack of a significant difference in consumption is in line with results from other recent studies by Essed et al. [8-10]. Their studies all used direct addition of MSG, either as a repeated exposure 16 week parallel study where study size was relatively low (approximately $n=20$ per group) [8], or as acute cross-over studies where there were higher numbers of participants $(n=53$ institutionalised adults and $n=120$ free lving older adults) [9, 10]. One of the main limitations of the current study was the small sample size of 31 participants. Considering the differences in the mean consumption between the control and taste-enhanced meals measured and the inter-subject variability (standard deviation), power calculations suggest that an adequate sample size to detect a difference significant at $5 \%$ with a power of $80 \%$ would be between 100 and 150 participants, depending on whether the output measure considered was protein or calorie intake.

The fact that the significant preference for the taste enhanced meat did not significantly increase consumption of the taste enhanced meal may imply the difference was insufficient. It is important to consider whether the increase in umami taste in the enhanced formulations was adequate. The content of umami compounds (glutamic acid, aspartic acid and $5^{\prime}$-adenosine monophosphate (5'-AMP), $5^{\prime}$ guanosine monophosphate $\left(5^{\prime}\right.$-GMP) and $5^{\prime}$-inosine monophosphate (5'-IMP)) and the calculated EUC were significantly higher in the enhanced minced meat base compared to the control meat (Table 1). This increase is due to presence of concentrated tomato extract and soy sauce in the enhanced samples [11]. 
The sensory discrimination tests confirmed that the enhanced minced meat base had significantly more umami taste than the control. However the difference between the pies with gravy was not significant, indicating that the mashed potato used on the cottage pie diluted the enhanced taste of the minced meat. This was further supported by the fact there was no significant difference between the EUC of the enhanced and control pies with gravy, although the content of umami amino acids were significantly higher in the enhanced pies (Table 1). Further increase of umami compounds with the ingredients used (soy sauce and concentrated tomato extract) was not possible, since it would have increased the sodium content in the final products. Moreover, the natural ingredients chosen for this study were based on previous research of this group where samples were tasted by old and young volunteers and also by trained sensory panellists [11], and a more suitable (well liked) combination of ingredients at a higher umami concentration (within a maintained sodium level) was not identified.

Each subject was presented with two identical plates which was overwhelming for some. Other studies which took place in retirement or nursing homes [6-10] gave subjects control and enhanced meals on separate days which avoided having to give them two servings in one day. However a crossover study is less feasible in a hospital setting where patient daily health status can vary substantially and people able to consent may be more likely to be discharged before the second study day.

Depression can affect food intake in older adults [15]. In this study there was a trend for those having a high depression score to have lower overall consumption, however this difference was not significant which may be attributed to the low number of participants in the study. Dentures did not have any significant effect on the consumption during this study $(P=0.76$; mean consumption for patients without dentures $275 \mathrm{~g}$ versus $242 \mathrm{~g}$ for patients with dentures) although they can sometimes effect taste due to partial occlusion of the palate and through negative impact on oral hygiene [16].

The subjects received only a single exposure to enhanced umami taste. A recent paper studied repeated exposure to novel flavoured soup with and without MSG on subsequent liking and consumption. An increase in liking and intake was found where subjects were exposed repeatedly to the soup with MSG over 4 consecutive days [17]. A physiological feedback from ingestion of glutamate, which increases liking and signals for increased consumption, was hypothesised.

In conclusion, this study found that increasing the umami taste of cooked minced meat using natural ingredients significantly increased preference by older hospital patients. However, the greater mean consumption of the taste enhanced meal was not significant. Future work should investigate the effect of repeated exposure to umami enhanced meals on consumption with a larger patient group.

\section{Acknowledgments}

The authors thank Research into Ageing for funding this project, patients and healthy participants, nursing and catering staff of Royal Berkshire NHS Foundation Trust.

\section{References}

[1] BAPEN's nutrition screening week 2011 [updated July 2012]. Available from http:/bapen.org.uk.

[2] Methven L, Allen VJ, Withers CA and Gosney MA. Ageing and Taste. ProcNutr Soc 2012;71(4):556-65.

[3] Schiffman SS. Taste and Smell Losses in Normal Aging and Disease. JAm Med Ass 1997;278(16):1357-62.

[4] Schiffman S, Graham B. Taste and smell perception affect appetite and immunity in the elderly. Eur J Clin Nutr 2000; 54:S54-S63.

[5] Kurihara K. Glutamate: From discovery as a food flavor to role as a basic taste (umami). Am J Clin Nutr 2009;90(3):719S-22.

[6] Schiffman SS. Sensory enhancement of foods for the elderly with monosodium glutamate and flavors. Food Rev Int 1998;14(2-3):321-33.

[7] Mathey M, Siebelink E, de Graaf C, Van Staveren WA. Flavor enhancement of food improves dietary intake and nutritional status of elderly nursing home residents. J Gerontology 2001; 56:M200-M5.

[8] Essed NH, van Staveren WA, Kok FJ, de Graaf C. No effect of 16 weeks flavor enhancement on dietary intake and nutritional status of nursing home elderly. Appetite 2007;48(1):29-36.

[9] Essed NH, Oerlemans P, Hoek M, et al. Optimal preferred MSG concentration in potatoes, spinach and beef and their effect on intake in institutionalized elderly people. J Nutr Health \& Aging 2009;13(9):769-75.

[10] Essed NH, Kleikers S, van Staveren WA, et al. No effect on intake and liking of soup enhanced with mono-sodium glutamate and celery powder among elderly people with olfactory and/or gustatory loss. Int J Food Sci Nutr 2009;60:143-54.

[11] Dermiki M, Mounayar R, Suwankanit C, et al. Maximising umami taste in meat using natural ingredients: Effects on chemistry and sensory perception. J Sci Food Agric 2013; 93:3312-21. 
[12] Yamaguchi S, Yoshikawa T, Ikeda S, Ninomiya T. Measurement of the relative taste intensity of some L-alpha-aminoacids and 5'-nucleotides. J Food Sci 1971;36:846-9.

[13] Food Standards Agency. Nutritional Guidelines for Food Served in Public Institutions: Food served to older people in residential care. Available from www.food.gov.uk, 2006.

[14] Barton AD, Beigg CL, MacDonald IA, Allison SP. High food wastage and low nutritional intakes in hospital patients. Clin Nutr 2000;19:445-9.
[15] Hickson M. Malnutrition and ageing. Postgrad Med J 2006;82(963):2-8.

[16] Solemdal K, Sandvik L, Willumsen T, Mowe M, Hummel T. The Impact of Oral Health on Taste Ability in Acutely Hospitalized Elderly. Plos One 2012;7(5).

[17] Yeomans MR, Gould NJ, Mobini S, Prescott J. Acquired flavor acceptance and intake facilitated by monosodium glutamate in humans. Physiol \& Behavior 2008;93(4-5):958-6. 